\title{
Life-time achievement award in life cycle assessment for Mark Goedkoop
}

\author{
Mark Huijbregts
}

Published online: 1 April 2014

(C) Springer-Verlag Berlin Heidelberg 2014

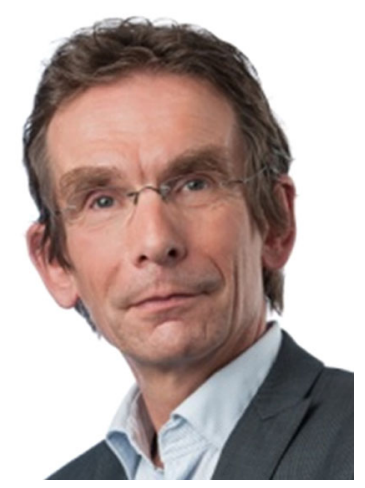

Mark Goedkoop is selected as the fifth recipient of the "Award for Life-time Achievement in Life cycle assessment".

He started as industrial design engineer in the " 80 s when interest for environmental issues started to grow. Mark understood that designers have great influence on the way a product is made, used and disposed of. In that time, the environmental discussion was dominantly led by emotions. Mark was looking for ways to rationalize the discussion and found out about a methodology called Life Cycle Assessment (LCA). Together with CML he was asked by the Dutch Ministry of Environment to organize a workshop on "environmentally sound design" and to create a software tool to explain the principles of LCA. That workshop marked the beginning of the LCA software SimaPro where many of us know him from.

Throughout the years, Mark has led many projects on the development of life cycle impact assessment (LCIA) methods. In the early nineties, the Eco-indicator 95 method was developed as the first single score method, which was both embraced and criticized. The Eco-indicator 99 followed and was using the latest scientific assessment models to create the first single score damage oriented impact assessment method. It also combined 3 different perspectives to acknowledge the fact that there are different views on reality. The ReCiPe method released in 2009 combined the endpoint approach of the Eco-indicator method with the midpoint approach of the CML method. Obviously, the development and implementation of these LCIA methods were not his sole work or achievement, as many others contributed to it. He, however, initiated many of the developments emphasizing his visionary way of thinking. More recently, he collaborated in the development of LCIA documents published in the ILCD Handbook and he contributed in the FP7 European research project LC-IMPACT to the development of LCIA methods for abiotic resource use.

With the ambition of harmonizing different standards and initiatives, Mark Goedkoop also participated in the Guidance for Product Category Rule Development. He has been contributing to the evaluation and provided recommendations to the development of the final Product and Organisation Environmental Footprint Guides developed by the European Commission. Currently, he is involved in the 3-year pilot phase of the development of Environmental Footprint rules. Mark is internationally well known through his contributions in ISO standards and the UNEP-SETAC Life Cycle Initiative.

Throughout his career, Mark Goedkoop has been very active to promote the development, understanding and acceptance of LCA worldwide. With this LTA award, we honour and pay rightful attention to his outstanding and ground breaking achievements in the field of life cycle assessment.

Mark Huijbregts on behalf of the SETAC Europe LCA steering committee. 